\title{
Associations Between Prosocial Behaviours, Gratitude, and Psychological Well-Being in Vulnerable Adolescents with Mild Intellectual Disabilities
}

Carmen Costea-Bărluțiu \& Georgiana Cătălina Boțu 


\title{
Associations Between Prosocial Behaviours, Gratitude, and Psychological Well-Being in Vulnerable Adolescents with Mild Intellectual Disabilities
}

\author{
Carmen Costea-Bărluțiu ${ }^{\text {a* }}$, Georgiana Cătălina Boțu ${ }^{\text {b }}$ \\ ${ }^{a}$ Department of Special Education, Faculty of Psychology and Educational Sciences, Babeș-Bolyai University, 7 Sindicatelor Street, Cluj-Napoca, \\ 400029, Romania \\ ${ }^{b}$ Faculty of Psychology and Educational Sciences, Babeș-Bolyai University, 7 Sindicatelor Street, Cluj-Napoca, 400029, Romania \\ *Corresponding author: carmen.costea@ubbcluj.ro
}

\section{Abstract}

\section{Keywords:}

prosocial behaviours, gratitude, well-being, adolescents, emotional problems, behaviour problems, problems with others.
The current research aims at exploring the associations between prosocial behaviours, psychological well-being and gratitude in a sample of adolescents identified as having problematic, challenging behaviours and mild intellectual disabilities. Various research results show that both gratitude and prosocial behaviours might have a significant role in the positive development in adolescents and adults. Using measures adapted on the Romanian population and some adapted for the current study, we collected data from a sample of 30 vulnerable, clinically healthy adolescents, enrolled in a special vocational school. We found low levels of gratitude and psychological well-being in our sample, as well as higher levels of emotional problems in girls compared to boys. Our results show that prosocial behaviours are significantly associated with lower peer problems, while prosocial behaviours and gratitude have a close to significance interaction effect on adolescents' well-being. Several possible implications both for research and clinical and educational practices in the service of vulnerable adolescents are discussed.

\section{Schlüsselworte:}

prosoziales

Verhalten;

Dankbarkeit;

Wohlbefinden;

Jugendliche;

emotionale

Probleme;

Verhaltensprobleme;

Probleme mit

anderen
Die aktuelle Forschung zielt auf die Untersuchung der Assoziation zwischen prosozialem Verhalten, psychologischem Wohlbefinden und Dankbarkeit in einer Stichprobe von Jugendlichen mit problematischem, herausforderndem Verhalten und leichter geistigen Behinderung. Verschiedene Forschungsergebnisse zeigen, dass sowohl Dankbarkeit als auch prosoziales Verhalten eine bedeutende Rolle in der positiven Entwicklung von Jugendlichen und Erwachsenen haben können. Anhand von Messungen, die der rumänischen Bevölkerung und der aktuellen Forschung angepasst wurden, haben wir Daten aus einer Stichprobe von 30 anfälligen, klinisch gesunden Jugendlichen erhoben, die eine besondere Berufsschule besuchten. Wir haben niedrige Niveaus von Dankbarkeit und psychologischem Wohlbefinden in der Stichprobe gefunden, aber auch höhere Niveaus von emotionalen Problemen unter Mädchen im Vergleich zu Jungen. Unsere Ergebnisse zeigen, dass prosoziales Verhalten erheblich mit weniger Peer-Problemen assoziiert ist, während prosoziales Verhalten und Dankbarkeit einen nahezu signifikanten Interaktionseffekt auf das Wohlbefinden der Jugendlichen haben. Einige mögliche Implikationen sowohl für die Forschung als auch für klinische und erzieherische Vorgehensweisen zu Gunsten der anfälligen Jugendlichen werden diskutiert.

\section{Introduction}

Historically, the positive psychology movement was a critique to the traditional perspective on human functioning, dominated by the biomedical model. The main purpose of positive psychology was to change the focus of professionals from the vulnerabilities to the qualities of human beings (Seligman \& Csikszentmihalyi, 2000). According to Seligman (2002), after the Second World War psychology became a science dedicated to a large extent to healing rather than prevention of illness. Several human forces and qualities can act as buffers against psychiatric illnesses: courage, optimism, interpersonal skills, faith, work ethics, hope, honesty, persistence, flow and understanding. Prevention means, to a large extent, finding ways to encourage these qualities in young population.

Various changes occur and are related to both psychological well-being and mental health in adolescence. Emotional, behavioural, social and communication changes are described during development in adolescence and various factors facilitate this process and protect the adolescent during this period, while other factors determine vulnerabilities in one or more areas of their life. Adolescence is a critical developmental period for mental and physical health risks, many symptoms of psychiatric illnesses become obvious at this vulnerable age, while the interest of health providers on adolescence is not enough (World Health 
Organization, 2019). Because various risks are prevalent during adolescence, this period is very important for prevention through healthy models and interventions, in order to eliminate the negative consequences of negative and risky behaviours on the adolescents' health and wellbeing (Call, Riedel, Hein, McLoyd, Petersen, \& Kipke, 2002).

\section{Theoretical foundation}

\subsection{Prosocial behaviours}

According to Fehr \& Fischbacher (2003), one of the most important differences that distinguish humans from other species are the abilities to help, cooperate and show altruism. Prosocial behaviours are defined as a large array of behaviours that produce benefits to others. Though individually costly, prosocial behaviours facilitate cooperation and are essential in human interaction (YostDubrow \& Dunham, 2018). In the literature, these behaviours are characterized by: (1) actions that have beneficial effects on others; (2) specific forms of motivations that determine behaviours that contribute to others' well-being (Batson, Ahmad, Lishner, \& Tsang, 2002, in Szentagotai-Tătar \& David, (coord.), 2017).

Early adolescence represents an important stage in the development of prosocial behaviours, as the opportunities for engagement in social activities, such as volunteering in organizations, that involve prosocial behaviours become more available (Fabes, Carlo, Kupanoff, Liable, 1999). The level of parental prosocial behaviours is positively related to the level of prosocial behaviours in children. Parental modelling of prosocial behaviours and the use of inductive discipline (the replacement of negative behaviours with more positive ones, in agreement with social norms, by understanding the consequences of inappropriate behaviours) are more efficient than assertive discipline, characterized by the use of authority and power in a positive manner (Eisenberg \& Fabes; 1998, Toiu-Ruiu, 2017). In some circumstances, the school environment and peer group hold significant influence on the adolescents' prosocial behaviour (Eisenberg \& Fabes, 1998).

Though the main purpose of prosocial behaviours is the well-being of others, several studies support the idea that they have beneficial effects on the person that performs them, both at mental and physical levels, on well-being and mental health (Szentagotai-Tătar \& David, (coord.), 2017). The mechanisms underlying this association are unclear, but one plausible explanation is the association of prosocial behaviours with positive emotions. Prosocial behaviours are associated with higher levels of gratitude, satisfaction, with lower mortality and morbidity (Szentagotai-Tătar \& David, (coord.), 2017), better psychological health (ex., lower levels of depression and anxiety).

\subsection{Gratitude}

Conceptualized both as personality trait and emotional state, as character strength and general attitude toward life (Emmons, 2007), gratitude implies being thankful for a gift of benefit offered by another person, destiny, God or other entity. Though a variety of experiences can be associated with gratitude, it is derived rather from the perception of a personal positive result, not necessarily earned or gained, due to the actions of another person (McCullough, Kimeldorf, \& Cohen, 2008). Fitzgerald (1998) identified three components of gratitude: 1) an honest feeling of appreciation for somebody or something; 2) a feeling of goodwill towards that person or thing; 3) a willingness to act, deriving from appreciation and goodwill.

Gratitude can be considered a moral emotion, because it has moral consequences and antecedents, originates and is manifested in prosocial acts (McCullough, Kilpatrick, Emmons, \& Larson, 2001). McCullough et al. (2001) developed the Theory of Moral Affect, that defines the moral functions of gratitude on three levels: (1) gratitude as moral barometer - the personal perception as beneficiary of a moral action performed by somebody else; (2) moral motive/ antecedent - the encouragement of others to engage in moral, prosocial behaviours, after they have been the beneficiaries of others' prosocial behaviours; (3) moral reinforcement - the perception of gratitude in the other as reinforcer for the moral, prosocial behaviours.

The capacity to be grateful is one of the strong points of an individual that can improve both the physical and the psychological health (Snyder \& McCullough, 2000). In support for this idea, Emmons \& McCullough (2003) found that daily thoughts of gratitude ("counting the blessings") for several weeks can significantly improve people's health and well-being.

Gratitude holds a role in motivating and reinforcing prosocial behaviour (Yost-Dubrow \& Dunham, 2018), by channeling positive emotions in prosocial behaviours and 
propagating actions made on behalf of others' well-being in communities (McCullough, Kimeldorf, \& Cohen, 2008). Also, the authors found a significant association between trait gratitude, generosity and trust in adults.

Graham (1988) and Peterson \& Stewart (1996), cited by McCullough, Kimeldorf, \& Cohen (2008) found that people who feel gratitude after a benefit have more chances to help both the benefactor and other persons and are more often engaging in prosocial behaviours than persons who feel gratitude less often. More grateful persons are less susceptible to engage in hostile, destructive behaviours, and gratitude is a factor that emphasizes prosocial behaviours, as well as a buffer against undesirable behaviours (Bartlett \& DeSteno, 2006). The purpose of gratitude is to stimulate prosocial acts toward a beneficiary, despite the costs of these acts (the action can be repetitive, unpleasant, tiring), to foster better, though frustrating decisions, that imply the postponement of rewards (DeSteno, Li, Dickens, \& Lerner, 2014), the so called delayed gratification.

\subsection{Psychological well-being}

In psychological research, various conceptualizations of psychological well-being are encountered, but none of them are exhaustive approaches. Two approaches are prevalent: (1) subjective well-being, emphasizing the need for happiness and pleasure, the presence of positive affect and absence of negative affect (hedonic well-being) and (2) psychological well-being, centered on a person's potential, emphasizing the need for full satisfaction in life (eudaimonic well-being) (Ryff \& Keyes, 1995; Keyes, Shmotkin \& Ryff, 2002, in Miron, 2011). Subjective wellbeing was associated with the experience of pleasure in real life situations, derived not only from physical hedonism, but also from the fulfillment of goals and results in various domains (Diener et al., 1998, in Ryan \& Deci, 2001). Psychological well-being is derived from the actualization of full potential, of own qualities and virtues, of true nature. The eudaimonic well-being calls for the implementation of deep values in daily life activities (Waterman, Schwartz, Goldbacher, Green, Miller, Philip, 1993). The two concepts share a common base, but also some specific features and, therefore, should be analyzed separately.

Persons that demonstrate higher levels of gratitude tend to also experience higher levels of subjective wellbeing, satisfaction, happiness and life satisfaction (Watkins, Woodward, Stone, \& Kolts, 2003). Grateful people enjoy life, reach higher levels of well-being, acknowledge more easily gifts and appreciate the people that made them.

Results from research that investigated the association between gratitude and well-being show that groups involved in performing gratitude exercises (ex., counting the blessings, naming things to be grateful for) have an increased good mood and well-being, compared with controls (Watkins et al., 2003). Moreover, there is evidence that these exercises have long term positive effects on well-being (6 months after treatment), lead to higher positive affect, lower negative effects and better life satisfaction (Seligman, Steen, Park, \& Peterson, 2005).

The association between prosocial behaviours and well-being has been documented in several studies and prosocial behaviours offer the highest emotional rewards when they facilitate social interactions (Dunn, Aknin, \& Norton, 2014). Prosocial behaviours are more likely to promote well-being when they are motivated by altruistic, rather than egoistic reasons. Other two factors that increase the benefits of prosocial behaviours are will and impact. When people feel forced to perform prosocial acts, they are not interpreted as beneficial to well-being (Weinstein \& Ryan, 2010).

Gender differences were identified regarding gratitude, subjective well-being and prosocial behaviour. Girls show higher gratitude than boys (Gordon, MusherEizenman, Holub, Dalrymple, 2004; Kashdan \& Silvia, 2009) and tend to have higher social benefits when grateful. Also, Eisenberg, Fabes, Miller, Fultz, Mathy, Shell, Reno (1989) reported that prosocial acts are more frequent in girls than in boys.

Very few studies investigated the nature of gratitude in adolescence and most research is focused on adult populations. Adolescents with intellectual disabilities were rarely included in research regarding gratitude, although they can be agents of gratitude (Gaventa, 2013). In agreement to previous research, our aim was to investigate the relationship between gratitude, prosocial behaviour and psychological health and well-being in vulnerable adolescents with mild intellectual disabilities, enrolled in special education programs. Gender differences in all these characteristics will be investigated. 


\section{Research methodology}

\subsection{Participants}

The initial sample included 41 vulnerable adolescents from a special school for mild intellectual disabilities with associated behavioural problems (various forms of aggressive behaviours, challenging oppositional problems, impulsivity etc.), aged 14 to 18 years (table no. 2 ), and most of the participants were 17 years old, with a mean age of 16.6 years. The selection criteria were developmental stage (age range corresponding to the adolescence period) and the presence of associated vulnerabilities (mild intellectual disability with disruptive, challenging behaviours). Other factors, such as academic results, did not constitute exclusion criteria. All the participants came from socially deprived environments, with low social-economic status, and none of them had a psychiatric diagnostic besides the identified challenging behavioural problems. Out of the 41 adolescents, 11 were eliminated from the study, on the grounds of the multiple missing values in the data collected from them, as well as the superficial approach in the completion of the questionnaires. Most of the teenagers were enrolled in the ninth grade (30\%) and tenth grade $(56.7 \%)$, in various programs offering vocational training to help them learn a profession and reach a level of social insertion according to their skills and intellectual capacities.

\subsection{Instruments and procedure}

The level of self-perceived difficulties and emotional and behavioural capacities was assessed using the Strengths and Difficulties Questionnaire (SDQ, Goodman, 2010, adapted for the Romanian population by Mateescu, Dobrean, Coposescu, Hofman, Muntean, Bogathy, 2014). The instrument has five subscales, each with 5 items, assessing emotional problems, conduct problems, hyperactivity, problems with others and prosocial behaviour. Each item is rated with a score ranging from "Not true" (0), to "Somewhat true" (1), and "Certainly true" (2). Although the questionnaire was developed for the age range of 11 to 17 years, we considered that it would be appropriate for the current study due to the presence of mild intellectual disability in our population of adolescents.

The assessment of the level of adolescents' well-being was performed using the Adolescent Well-Being Scale ( $A W B S$, Birleson, 1981), an instrument derived from the
Depression Self-rating Scale for Children and it assesses the risk of depressive symptoms in older children and adolescents, aged 11 to 16 years. The questionnaire includes 18 items, each referring to different aspects of a teenager's life and the way in which they feel about it. The teenagers are asked to assess whether the statement applies to them "most of the time" (0), "sometimes" (1) or "never" (2). In our study, higher scores indicate higher risk of depressive symptoms. The authors found a cut-off score of 13 points for the risk of depressive symptoms in adolescents, but other sources of information are necessary in order to make a diagnosis.

The level of gratitude was assessed using The Gratitude Questionnaire-Six Item Form (GQ-6, McCullough, Emmons, \& Tsang, 2002). The questionnaire is a self-report measure, used to assess the individual differences in gratitude in everyday life. The participants rated their answers to each item on a 7-point Likert scale, from 1 (strongly disagree) to 7 (strongly agree). The short measure of gratitude is one of the most often used measure of gratitude in research on young populations, college students (ex., McCullough, Emmons, \& Tsang, 2002) and high school students (ex., Chen \& Kee, 2008), healthy populations or clinical samples (ex., Kashdan, Uswatte, \& Julian, 2006).

All measures were given to the teenagers in a written format and they completed them in the presence of the second author, in small groups, in a paper and pencil form. Some participants needed small amount of guidance in completing the measures, and minimal support was given to them in order to understand the instructions, but the influence in answering was avoided. Due to the presence of the behavioural problems, several sessions were needed for the completion of the whole battery, as in most cases there was behavioural interference with the assessment (refusal of the material, aggressive approach of the examiner, leaving the desk, verbal comments etc.).

\section{Results}

\subsection{Internal consistencies of the measures}

All the instruments proved to have a weak internal consistency and, therefore, we eliminated some of the items in several of the subscales (table no. 1), until the value of alpha Cronbach quotient improved, and the remaining values were close to acceptable. The possible explanation for the problems we encountered with some of the items could be the presence of the mild intellectual 
disability, along with several cultural differences that impeded the decoding of the item meaning by the participants. Thus, some of the subscales, such as the Peer problems subscale from the SDQ, ended up with a very small number of items, a number too small for the subscale to be a reliable measure of the construct, so the results should be interpreted with caution. The items of the subscale referred to heterogenous types of behaviours that reflected problems with peer group, so they could be hard to understand for the participants. We eliminated from the data analysis the Hyperactivity subscale because it had a very low internal consistency in our study group, and we could not improve the value of alpha Cronbach by eliminating items.

Table no. 1. Internal consistencies of the measures used in the study

\begin{tabular}{|c|c|c|c|c|}
\hline Scale & Subscale & Alpha Cronbach & Eliminated items & $\begin{array}{c}\text { Nr. of remaining } \\
\text { items }\end{array}$ \\
\hline \multirow[t]{4}{*}{ SDQ } & Emotional problems & .662 & - & 5 \\
\hline & Conduct problems & .528 & 22 & 4 \\
\hline & Peer problems & .637 & $6,19,23$ & 2 \\
\hline & Prosocial & .780 & - & 5 \\
\hline AWBS & & .677 & 3 & 16 \\
\hline GQ-6 & & .613 & 1 & 5 \\
\hline
\end{tabular}

The remaining items in each of the subscales were summed to obtain the total scores. However, the construct operationalizations were modified, to correspond to the specific of our study, and the results obtained for the corresponding subscales are questionable and need further testing in other studies.

\subsection{Levels of the adolescents' well-being, prosocial behaviors and gratitude}

One interesting result was the level of well-being of the teenagers included in our research. Comparing the scores that we obtained with the cutoff score provided by the authors of the scale, we found a high level of risk for depression. Although we eliminated one of the items due to low Cronbach's Alpha value of the scale, the overall scores were close to 13 , the cutoff score provided by the authors of the scale, as seen in their distribution presented in figure no. 1. A high number of adolescents from our study presented emotional problems, the female participants scoring significantly higher in emotional problems (table no. 2, figure no. 2). Also, the adolescents who reported higher overall difficulties in their life (as measured with the SDQ scale) also scored significantly higher in terms of emotional problems (table no. 2).

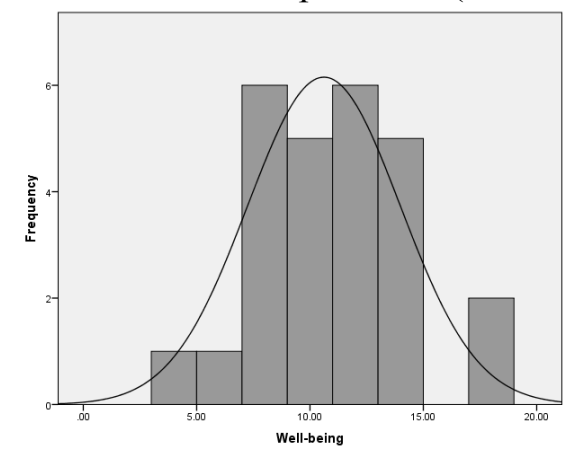

Figure no. 1. Distribution of the participants' scores for well-being
The interesting fact about our results was that our female participants scored significantly higher compared to male participants regarding their emotional problems. Although our sample was formed by vulnerable adolescents with behavioural difficulties, it seems that their reported scores for conduct problems are not very high, and are similar for boys and girls, while their level of emotional problems is much higher and similar to the scores that other authors found in clinical samples of teenagers, using the same measure we used, adapted for Romanian population of teenagers. Figure no. 2 also shows that a number of adolescents in our sample, mostly girls, reported levels of emotional problems that can raise concerns about their emotional state.

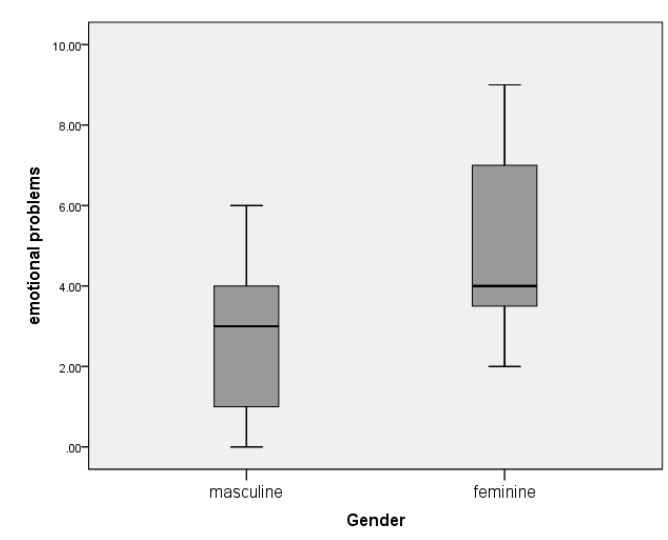

Figure no. 2. Comparison between the emotional problems scores of girls and boys

At the same time, the self-reported scores for prosocial behaviours were high, showing the tendency of the teenagers to have positive effects and do good to others, but at the same time their high vulnerability towards mental health problems, especially emotional vulnerabilities. Regarding the level of gratitude, we found 
lower scores in our sample, compared to the scores reported by other authors on college students. We eliminated one item of the scale, in order to increase the internal consistency, but even so our average scores are much lower. Gils tended to show a slightly higher level of gratitude, compared to boys, but the differences were not statistically significant.

Table no. 2. Descriptives and scores obtained by the participants for the various measures

\begin{tabular}{|c|c|c|c|c|c|c|c|c|}
\hline & \multirow{2}{*}{\multicolumn{2}{|c|}{ Freq. }} & \multicolumn{6}{|c|}{ M(SD) } \\
\hline & & & EmProbl & CondProbl & PeerProbl & Prosocial & AWBS & GQ-6 \\
\hline \multirow[t]{2}{*}{ gender } & male & $56.67 \%$ & $2.59(2.1)$ & $3.76(1.9)$ & $1.35(1.2)$ & $7.24(2.3)$ & $13.41(3.82)$ & $18.06(5.9)$ \\
\hline & female & $43.33 \%$ & $5.18(2.4)^{* *}$ & $3.38(1.8)$ & $1.54(1.1)$ & $6.92(2.6)$ & $12.84(3.99)$ & $21.08(3.8)$ \\
\hline \multirow[t]{2}{*}{ difficulties } & no & $43.33 \%$ & $2.54(2.2)$ & $3.46(1.9)$ & $1.69(1.4)$ & $6.62(2.3)$ & $13.46(3.9)$ & $18.62(4.3)$ \\
\hline & yes & $56.66 \%$ & $4.53(2.4)^{* *}$ & $3.71(1.8)$ & $1.24(.9)$ & $7.47(2.4)$ & $12.94(3.3)$ & $19.94(6.0)$ \\
\hline
\end{tabular}

\subsection{Correlations and complex associations between the characteristics}

A high number of studies found significant associations between gratitude, prosocial behaviours and well-being in adolescents and adults, but we found no such associations in our study. The only significant negative association was between prosocial behaviours and peer problems (table no. 3), meaning that adolescents who show prosocial behaviours tend to have friends and be liked by their peers. Similar results were found by Caputi et al. (2012), who also reported significant changes in reducing peer rejection and increasing acceptance in teenagers who participate in programs that target the increase of prosocial behaviours.

Table no. 3. Correlations between reported problems, well-being and gratitude

\begin{tabular}{|c|c|c|c|c|c|c|}
\hline Scale & & 1 & 2 & 3 & 4 & 5 \\
\hline \multirow[t]{2}{*}{ EmProbl } & $\mathbf{r}$ & .104 & & & & \\
\hline & $\mathbf{p}$ & .599 & & & & \\
\hline \multirow[t]{2}{*}{ CondProbl } & $\mathbf{r}$ & -.242 & .251 & & & \\
\hline & p & .198 & .197 & & & \\
\hline \multirow[t]{2}{*}{ PeerProbl } & $\mathbf{r}$ & .147 & -.078 & -.301 & & \\
\hline & $\mathbf{p}$ & .439 & .695 & .106 & & \\
\hline \multirow[t]{2}{*}{ Prosocial } & $\mathbf{r}$ & .014 & -.087 & .065 & $-.381^{*}$ & \\
\hline & $\mathbf{p}$ & .943 & .658 & .733 & .038 & \\
\hline \multirow[t]{2}{*}{ AWBS } & $\mathbf{r}$ & -.170 & -.296 & -.116 & .099 & -.023 \\
\hline & $\mathbf{p}$ & .369 & .126 & .540 & .601 & .905 \\
\hline
\end{tabular}

1-GQ-6, 2 - EmProbl, 3 - CondProbl, 4 - PeerProbl, 5 - Prosocial, 6 - AWBS * Significant $(\mathrm{p}<.05)$

Although a little below significant threshold, we found a moderation effect of gratitude and prosocial behaviour on the overall well-being in our sample of teenagers. Only 26 of the total number were included in the analysis, due to missing values. We used Process Macro for SPSS to conduct the analysis (Hayes, 2018). We found that the variation in overall well-being was partly accounted for by the interaction between the two variables included in our analysis: $\mathrm{R}^{2}=.29, \mathrm{~F}(3,22)=2.997, \mathrm{p}=.052$. After adding the interaction term, a significant proportion of the variance in the dependent variable was found, $\Delta \mathrm{R}^{2}=$ $.165, \Delta \mathrm{F}(1,22)=5.13, \mathrm{p}<.05, \mathrm{~b}=-.11, \mathrm{t}(22)=-2.26$, $\mathrm{p}<.05$. Although slightly below statistical significance, we decided to report the effect due to its possible clinical relevance. It seems that in our small sample of highly vulnerable adolescents, identified as having behavioural problems, we could find high levels of emotional problems, low level of well-being, equivalent with high risk for depressive symptoms, but few associations, contrary to what other authors reported, between emotional health, prosocial behaviours and gratitude. However, there can be a possible diminishing effect of the interaction between gratitude and prosocial behaviours on the level of risk for depression. This effect should be further tested, as our results were calculated on small samples, and the self-report instruments proved to have low internal consistency.

\section{Discussions}

Based on our data and results, we can conclude that in our vulnerable population of adolescents the association found by other authors between gratitude, psychological well-being and prosocial behaviours is not obvious. We found in our sample of adolescents, identified as having various challenging problematic behaviours in schools and outside of the school, high scores of emotional problems, similar to the ones reported by other authors on 
clinical samples of adolescents who manifested suicidal ideation and attempts (Cotter et al., 2015), higher than scores found in adolescents with pathological use of internet (Strittmatter et al., 2015) and high risk of depression, similar to the cutoff scores reported by the authors of the measure we used (Birleson, 1980). The scores of our participants for gratitude were much lower than the scores reported by other authors on samples of college students (ex., Chen, Chen, Kee, \& Tsai, 2008, Kashdan \& Breen, 2007 etc.). Studies examining these relations in adolescents are not that numerous, compared to research on adults, and populations of vulnerable adolescents are even less likely to be included in research. Consistent with research on adults, Froh, Sefick, \& Emmons (2008) found that gratitude induction using the counting blessings technique was related to enhanced well-being, optimism, life satisfaction, less negative affect and higher satisfaction with school experience in early adolescents and the effects are long lasting. Also, Froh, Bono, \& Emmons (2010) reported that gratitude predicted social integration, while prosocial behaviour and life satisfaction mediated the relation, showing that gratitude might have a significant role in fostering the adolescents' positive development toward better wellbeing. Based on our results, we consider that gratitude alone would not be enough to increase psychological well-being, but in interaction with prosocial behaviours we think that it could constitute a basis for effective intervention in reducing emotional problems of vulnerable adolescents.

A similar result to what other authors (ex., Layous, Nelson, Oberle, Schonert-Reichl, \& Lyubomirsky, 2012) found was that prosocial behaviour is significantly associated with less problems with peers. However, in our study being liked by others and having friends did not associate with better psychological well-being. It seems like vulnerable adolescents need much more than good relationships with peers and positive behaviours towards them in order to be psychologically healthy.

Being prosocial was reportedly high in our sample, but gratitude was assessed much lower that that found in other samples. It might be possible that the adolescents in our study didn't have the concept of gratitude learned and exercised, given that the applications of positive psychology in education are at their beginning. Often, behavioural modification techniques that target problematic behaviours are implemented, but the emotional basis of these behaviours might remain unknown. Our results show that adolescents identified as having challenging behaviours face high emotional problems (especially girls in our sample) and low psychological well-being.

Several limitations of our study need to be mentioned as basis for cautionary interpretation of the results, as well as basis for the need for future studies. The small number of participants, the selection manner (by convenience), as well as the high heterogeneity are sample characteristics that might constitute sources of bias in our results. A second limitation is the fact that the measures, although some (the subscales of the SDQ) were adapted for Romanian population, proved to have low internal consistency in our sample of vulnerable adolescents and need further testing in order to be adequately culturally adapted on Romanian population.

Other studies might implement our results in counselling programs based on positive psychology, so that vulnerable adolescents can feel the benefits of gratitude, prosocial behaviour on their psychological well-being and health. We consider the topic as very promising for both research and practice and therefore suggest as possible direction for research the deepening of our results, the expansion by including other variables and the generalization by replicating our results on larger samples.

\section{Conclusions}

Although a plethora of literature exists on the effect of gratitude on mental health, very few studies included adolescents with various disabilities and vulnerabilities. Our results show that research on the role of gratitude on mental health could be applied in both research and practice with vulnerable adolescents, in both assessment and interventions targeting the improvement of their wellbeing. Educational programs provided for this category of young population, at risk for various mental health problems, should, in our opinion, include elements from positive psychology applied as therapeutic and preventive techniques, that could prove effective in the management of their behaviours and emotional problems. 


\section{Authors note:}

Carmen Costea-Bărluțiu (special educator and psychotherapist) is currently a Lecturer in the Department of Special Education, School of Psychology and Educational Sciences, Babeș-Bolyai University, ClujNapoca, Romania and a systemic couple and family psychotherapist in private practice. Her interests and training in psychotherapy include: Ericksonian Hypnotherapy, Schema-focused therapy, Mentalizationbased treatment, Attachment-based interventions. She has professional and research interests in: attachment theory in human development and psychotherapy, parenting and disability, systemic psychotherapy and family well-being.

Boțu Georgiana Cătălina is currently a MA student at Babeș-Bolyai University, enrolled in the Management, Counselling and Special Educational Assistance master program at the Department of Special Education, School of Psychology and Educational Sciences, Cluj-Napoca, Romania. Her research and practical interests are Positive Psychology, psychodrama, disability and its impact on the well-being and mental health. At present, she works as a special educator with children with Down Syndrome and children Autism Spectrum Disorder in a special education institution

\section{References}

Bartlett, M.Y., DeSteno, D. (2006). Gratitude and Prosocial Behavior. Helping When It Costs You. Psychological Science, 17(4), pp. 319-325.

Birleson, P. (1980). The validity of Depressive Disorder in Childhood and the Development of a Self-Rating Scale. A Research Report. Journal of Child Psychology and Psychiatry, 22, pp. 73-88.

Call, K.T., Riedel, A.A., Hein, K., McLoyd, V., Petersen, A., \& Kipke, M. (2002). Adolescent Health and Well-Being in the Twenty-First Century: A Global Perspective. Journal of Research on Adolescence, 12(1), pp. 69-98.

Chen, L.H., Chen, MY., Kee, Y.H., \& Tsai, Y.-M. (2009). Validation of the Gratitude Questionnaire (GQ) in Taiwanese Undergraduate Students. Journal of Happiness Studies, 10, pp. 655-664.

Cotter, P., Kaess, M., Corcoran, P., Parzer, P., Brunner, R., Keeley, H., Carli, V., Wasserman, C., Hoven, C., Sarchiapone, M., Apter, A., Balazs, J., Bobes, J., Cosman, D., Haring, C., Kahn, J.-P., Resch, F., Postuvan, V., Varnik, A., \& Wasserman, D. (2015). Help-seeking behaviour following school-based screening for current suicidality among European adolescents. Social Psychiatry and Psychiatric Epidemiology, 50(6), pp. 973-982.
DeSteno, D.,Li,Y., Dickens, L., \& Lerner, J.S. (2014). Gratitude. Psychological Science, 25(6), pp. 1262-1267.

Dunn, E., Aknin, L., \& Norton, M. (2014). Prosocial Spending and Happiness: Using Money to Benefit Others Pays Off. Current Directions in Psychological Science. 23, pp. 41-47.

Eisenberg, N., Fabes, R.A. (1998). Prosocial development. In W. Damon (Ed.) and N. Eisenberg (Vol. Ed.). Handbook of child psychology: Vol. 3. Social, emotional, and personality development ( $5^{\text {th }}$ Ed.), New York: Wiley.

Eisenberg, N., Fabes, R.A., Miller, P.A., Fultz, J., Mathy, R.M., Shell, R., \& Reno, R.R. (1989). The relations of sympathy and personal distress to prosocial behavior: A multimethod study. Journal of Personality and Social Psychology, 57, pp. 55-66.

Emmons, R.A. (2007). Thanks! How the new science of gratitude can make you happier. New York: HoughtonMifflin.

Emmons, R.A., McCullough, M.E. (2003). Counting blessings versus burdens: An experimental investigation of gratitude and subjective well-being in daily life. Journal of Personality and Social Psychology, 84(2), pp. 377-389.

Fabes, R., Carlo, G., Kupanoff, K., \& Liable, D. (1999). Early adolescence and prosocial/ moral behavior I: The role of individual processes. Journal of Early Adolescence, 19(1), 516.

Fehr, E., Fischbacher, U. (2003). The nature of human altruism. Nature, 425, pp. 785-791.

Fitzgerald, P. (1998). Gratitude and justice. Ethics, 109, pp. 119-153.

Froh, J.J., Bono, G., \& Emmons, R. (2010). Being grateful is beyond good manners: Gratitude and motivation to contribute to society among early adolescents. Motivation and Emotion, 34, pp. 144-157.

Froh, J.J., Sefick, W.J., \& Emmons, R.A. (2008). Counting blessings in early adolescents: An experimental study of gratitude and subjective well-being. Journal of School Psychology, 26, pp. 213-233.

Gaventa, W. (2013). Forgiveness, Gratitude, and Spirituality. In M.L. Wehmeyer (Ed.). The Oxford Handbook of Positive Psychology and Disability. Oxford, UK: Oxford University Press.

Gordon, A.K., Musher-Eizenman, D.R., Holub, S.C., \& Dalrymple, J. (2004). What are children thankful for? An archival analysis of gratitude before and after the attacks of September 11. Journal of Applied Developmental Psychology, 25(5), pp. 541-553.

Hayes, A.F. (2018). Introduction to Mediation, Moderation, and Conditional Process Analysis: A Regression-Based Approach, Second Edition, New York: The Guilford Press.

Kashdan, T. Silvia, P. (2009). Curiosity and Interest: The Benefits of Thriving on Novelty and Challenge. In S.J. Lopez (Ed.). Handbook of Positive Psychology (2 ${ }^{\text {nd }}$ Ed.), Oxford, UK: Oxford University Press.

Kashdan, T.B., Breen, W.E. (2007). Materialism and Diminished Well-Being: Experiential Avoidance as a Mediating Mechanism. Journal of Social and Clinical Psychology, 26(5), pp. 521-539.

Kashdan, T.B., Uswatte, G., \& Julian, T. (2006). Gratitude and hedonic and eudaimonic well-being in Vietnam War veterans. Behaviour Research and Therapy, 44(2), pp. 177-199. 
Layous, K., Nelson, K., Oberle, E., Schonert-Reichl, K.A., \& Lyubomirsky, S. (2012). Kindness Counts: Prompting Prosocial Behavior in Preadolescents Boosts Peer Acceptance and Well-Being. PLOS ONE, 7(12), pp. 1-3.

Mateescu, L., Dobrean, A., Coposescu, L., Hofman, M., Muntean, A., \& Bogathy, Z. (2014). Romanian version of Strengths and Difficulties Questionnaire, published online sdqinfo.com/py/sdqinfo/b3.py?language=Romanian.

McCullough, M.E., Emmons, R.A., \& Tsang, J.-A. (2002). The grateful disposition: A conceptual and empirical topography. Journal of Personality and Social Psychology, 82(1), pp. 112127.

McCullough, M.E., Kimeldorf, M.B., \& Cohen, A.D. (2008). An Adaptation for Altruism. Current Directions in Psychological Science, 17(4), 281-285.

Mccullough, M., Kilpatrick, S., Emmons, R., \& Larson, D. (2001). Is Gratitude a Moral Affect?. Psychological bulletin. 127, pp. 249-266.

Miron, M.I. (2011). Satisfacția față de viață și spiritualitatea: implicații pentru starea psihologică de bine a individului. Romanian Journal of Applied Psychology, 13(2), pp. 50-55.

Ryan, R.M., Deci, E.L. (2001). On Happiness and Human Potentials: A Review of Research on Hedonic and Eudaimonic Well-Being. Annual Review of Psychology, 52(1), pp. 141-166.

Seligman, M.E.P. (2002). Positive psychology, positive prevention, and positive therapy. In C.R. Snyder, S.J. Lopez (Eds.). Handbook of positive psychology. New York: Oxford University Press.

Seligman, M.E.P., Csikszentmihalyi, M. (2000). Positive psychology. An introduction. American Psychologist, 55(1), pp. 5-14.

Seligman, M.E., Steen, T.A., Park, N., \& Peterson, C. (2005). Positive psychology progress: Empirical validation of interventions. American Psychologist, 60(5), pp. 410-421.

Snyder, C.R., McCullough, M. (2000). A positive psychology field of dreams: "If you build it, they will come...". Journal of Social and Clinical Psychology, 19(1), pp. 151-160.
Strittmatter, E., Kaess, M., Parzer, P., Fischer, G., Carli, V., Hoven, C.W., Wasserman, W., Sarchiapone, M., Durkee, T., Apter, A., Bobes, J., Brunner, R., Cosman, D., Sisask, M., Varnik, P., \& Wasserman, D. (2015). Pathological internet use among adolescents: Comparing gamers and non-gamers. Psychiatry Research, 228(1), pp. 128-135.

Szentagotai-Tătar, A., David, D. (coord.) (2017). Tratat de psihologie pozitivă. Iaşi: Editura Polirom.

Toiu-Ruiu, R.P. (2017). Relația dintre comportamentul prosocial al preșcolarilor, afectul incidental, statutul socioeconomic și costul ajutorului. Revista de psihologie, 63(4), pp. 232-244.

Waterman, A.S., Schwartz, S.J., Goldbacher, E., Green, H., Miller, C., \& Philip, S. (1993). Predicting the subjective experience of intrinsic motivation: The roles of selfdetermination, the balance of challenges and skills, and selfrealization values. Personality and Social Psychology Bulletin, 29, pp. 1447-1458.

Watkins, P.C., Woodward, K., Stone, T., \& Kolts, R.L. (2003). Gratitude and happiness: Development of a measure of gratitude, and relationships with subjective well-being. Social Behavior and Personality: An International Journal, 31(5), pp. 431-451.

Weinstein, N., Ryan, R.M. (2010). When helping helps: Autonomous motivation for prosocial behavior and its influence on well-being for the helper and recipient. Journal of Personality and Social Psychology, 98(2), 222-244.

Yost-Dubrow, R., Dunham, Y. (2018). Evidence for a relationship between trait gratitude and prosocial behaviour. Cognition and Emotion, 32(2), pp. 397-403

*** World Health Organization (2019). Adolescent Health: Missing Population in Universal Health Coverage, who.int/ Available at: https://www.google.com/search?client=firefoxb-

$\mathrm{d} \& \mathrm{q}=$ Health + Organization $+\% 282019 \% 29 .+$ Adolescent $+\mathrm{He}$ alth $\% 3 \mathrm{~A}+$ Missing + Population + in + Universal + Health + Cover age (accessed at 24.11.2019). 